\title{
Oral and Dental Manifestations of Fanconi Anemia
}

\author{
Vesna Ambarkova (D)
}

\begin{abstract}
Fanconi anemia is a rare disease, which is characterized by decreased production of all blood cell types. Fanconi anemia is the most common inherited form of aplastic anemia. Congenital abnormalities of the eyes, ears, and heart, malformed or absent kidney, urogenital system involvement are common. There is a delay in physical development. Intelligence in patients with Fanconi anemia is usually normal. The most serious problems associated with Fanconi anemia include the gradual development of bone marrow disorders. Many patients with Fanconi anemia develop leukemia or myelodysplastic syndrome, as well as other oncological diseases. Oral manifestations in patients with Fanconi anemia can be classified as gingivitis, periodontitis, dental caries, dental anomalies, soft tissue lesions, oral cancer, and lesions of the tongue. Patients with Fanconi anemia have increased predisposition to squamous cell carcinoma of the head and neck and oral cancer. The interdisciplinary team of medical and dental specialists must be included in the medical and dental treatment of patients with Fanconi anemia. For proper dental care of patients with Fanconi anemia, the close cooperation of dental specialists, including orthodontists, pedodontists, prosthetists, oral surgeons, as well as specialists in periodontology and oral diseases, is of particular importance.
\end{abstract}

\section{Keywords}

Fanconi Anemia; Caries Experience; Dental Caries; Special Dental Care

Department of Paediatric and Preventive Dentistry, Faculty of Dental Medicine, Saints Cyril and Methodius University, Skopje, Republic of North Macedonia

*E-mail: vesna.ambarkova@gmail.com

\section{Introduction}

Fanconi anemia (FA) is a rare disease, which bears the name of the famous Swiss paediatrician Guido Fanconi, who first discovered the disease [1]. The average birth rate of children with FA is approximately 1 case per 350, 000 newborns. It occurs with the same frequency in both males and females, among all nationalities [1]. FA is a congenital disorder that is inherited in an autosomal recessive manner, i.e., if the father and mother are carriers of the defective gene (they can be completely clinically healthy), then, with each delivery, there is a $25 \%$ risk for a child to have this disease. There is a lack of literature dealing with the most prevalent oral manifestations seen in patients with FA. The incidence of FA is increasing in communities of people where marriages are closely related. At least 22 faulty genes are associated with FA [2]; however, new deletions of already known genes are still being discovered [3]. Since the treatment of this rare disease requires a multidisciplinary approach, dentists' knowledge about early diagnosis and appropriate treatment of oral manifestations, as well as prevention of squamous cell carcinoma is of particular importance.

The objective of this review was to focus on the literature dealing with oral changes and their relationship to the overall health and well-being of patients with FA from the dentist's point of view.

\section{Signs and Symptoms}

Congenital aplastic anemia is usually diagnosed at 4 to 12 years of age through pancytopenia. It can occur as isolated anemia, or anemia with co-existent leukopenia or thrombocytopenia. Children with FA often develop characteristic physical anomalies: skeletal malformations (e.g., thumbs, wrist bones, thighs, spine, ribs), short stature, bird-headed facial appearance, skin changes - hypopigmentation, light-todark-brown coffee-colored skin. Congenital abnormalities of the eyes, ears, and heart, malformed or absent kidney, urogenital system involvement are common $[4,5]$. There is a delay in physical development. Intelligence in patients with FA is usually normal. More than $50 \%$ of patients have physical abnormalities. These also may include brain malformations 
(small head size, excess fluid in the brain), genital abnormalities [5].

The most serious problems associated with FA include the gradual development of bone marrow disorders. They usually become noticeable at the age of 5-10 years and, then, worsen over time, although sometimes the disease is almost asymptomatic for many years. Decreased platelet count leads to increased bleeding (easy bruising and nasal bleeding); decreased red blood cell count leads to weakness and fatigue; decreased leukocyte count (neutrophils) leads to poor resistance to infections. Many patients develop leukemia or myelodysplastic syndrome [6], as well as other oncological diseases $[2,7]$.

\section{Oral Manifestations of FA}

Thrombocytopenia seen in patients with FA promoted inflammation of the gums, especially considering the fact that these patients have undergone long-term hospital treatment since early childhood, where there were no adequate conditions for maintaining oral hygiene [8]. According to Gaitán-Fonseca C, there is no epidemiological data on the incidence of FA in Mexico and many cases remain undiagnosed. After applica- tion of the obturator over the palatal cleft, a significant reduction in the ear, tonsil and throat infections was noticed [9].

In patients with FA, especially after hematopoietic stem cell transplantation (HSCT), there is an increased risk of malignant diseases of the oral cavity. A wide range of oral manifestations occurring in patients with FA is shown in Table 1. Calcineurin inhibitors are medications commonly used for long periods of time in patients undergoing allogeneic HSCT. Cases of children with FA, who developed similar oral mucosal lesions associated with the use of cyclosporine, phenobarbital, and amlodipine after HSCT, have been described in the literature [10]. Patients with FA have increased predisposition to squamous cell carcinoma of the anogenital tract and head and neck region [11]. In addition, many studies have linked FA to oral cancer [7, 12, 13] and some have assessed the risk of developing oral cancer [14, 15].

Lyko K et al. from Brazil conducted a comparative study including 35 patients with FA and 35 healthy individuals (the control group) to investigate the difference between their dental caries experience, dental care level, and oral hygiene. In their study, FA patients demonstrated higher values of the decay-missing-filled index (DMFI), the dental care index, the oral hygiene index; however, there was no statistically

Table 1. Clinical studies on oral and dental manifestations of Fanconi anemia.

\begin{tabular}{|c|c|c|c|c|}
\hline No. & Authors & Patients & Key Oral Findings & Reference \\
\hline 1. & Touil D et al. & Ten-year-old boy & Microdontia and advanced periodontitis & $\begin{array}{l}\text { [8] Case Reports in } \\
\text { Dentistry. } \\
\text { 2020;2020:3161053. }\end{array}$ \\
\hline 2. & Gaitán-Fonseca $\mathrm{C}$ et al. & Newborn & Cleft palate & $\begin{array}{l}\text { [9] Odovtos-Int J Dent } \\
\text { Sc. } 2018 ; 20(3): 25-31\end{array}$ \\
\hline 3. & Ballardin BS et al. & $\begin{array}{l}\text { Six-twelve-year- } \\
\text { old patients }\end{array}$ & $\begin{array}{l}\text { Medication-related fibrovascular hyper- } \\
\text { plasia }\end{array}$ & $\begin{array}{l}\text { [10] Pediatric } \\
\text { Transplantation. } 2020 .\end{array}$ \\
\hline 4. & Kaul R et al. & $\begin{array}{l}\text { Three-year-old } \\
\text { female child }\end{array}$ & Spontaneous gingival bleeding at night & $\begin{array}{l}\text { [17] SRM J Res Dent } \\
\text { Sci. 2017;8(2):92-96. }\end{array}$ \\
\hline 5. & Miranda $\mathrm{F}$ et al. & $\begin{array}{l}\text { Eight-year-old } \\
\text { female patient }\end{array}$ & $\begin{array}{l}\text { Class III skeletal pattern and maxillary } \\
\text { lateral incisor agenesis }\end{array}$ & $\begin{array}{l}\text { [18] Special Care in } \\
\text { Dentistry. } \\
\text { 2020;40(4):382-389. }\end{array}$ \\
\hline 6. & Goswami M et al. & $\begin{array}{l}\text { Five-year-old } \\
\text { male patient }\end{array}$ & $\begin{array}{l}\text { Mesiodens, retained deciduous mandibu- } \\
\text { lar incisors and delayed eruption of } \\
\text { permanent mandibular incisors, white } \\
\text { patches on the dorsal surface of the } \\
\text { tongue, traumatic bite lesions with de- } \\
\text { layed healing on the cheek and tongue }\end{array}$ & $\begin{array}{l}\text { [19] Clinical Medicine } \\
\text { Insights: Case Reports. } \\
\text { 2016;9:CCRep.S37931. }\end{array}$ \\
\hline 7. & Perdoncini NN et al. & $\begin{array}{l}\text { Fifty-six patients } \\
\text { with FA over } 11 \\
\text { years of age }\end{array}$ & $\begin{array}{l}\text { The average DMFI }=5.23, \text { the Visible } \\
\text { Plaque Index }=31.36 \% \text { and the Gingival } \\
\text { Bleeding Index }=33.77 \%\end{array}$ & $\begin{array}{l}\text { [20] Hematology, } \\
\text { Transfusion and Cell } \\
\text { Therapy. } 2020 .\end{array}$ \\
\hline 8. & de Araujo MR et al. & $\begin{array}{l}\text { Thirty-three } \\
\text { patients }\end{array}$ & $\begin{array}{l}\text { Melanin pigmentation in the oral mucosa, } \\
\text { traumatic lesions, agenesis, taurodontism, } \\
\text { radicular anomalies such as dilaceration, } \\
\text { tapering, and foreshortening, gingival } \\
\text { bleeding, dental biofilm, and gingival al- } \\
\text { terations }\end{array}$ & $\begin{array}{l}\text { [21] Oral Diseases. } \\
\text { 2007;13(3):291-295. }\end{array}$ \\
\hline
\end{tabular}


significant difference between the groups [16]. Several case reports of FA patients of different ages have been described in the literature [17]. The individual approach to dental treatment depended on the oral health status and the need for orthodontic treatment [18].

In a case report of a 5-year-old male from India, Goswami $\mathrm{M}$ et al. described the presence of mesiodens in the lower jaw, which is very rare. Delayed tooth eruption, as well as other dental anomalies were also present. Hyposalivation was common in FA patients due to endocrine dysfunction, which further increased the susceptibility to dental caries in these patients [19]. Recurrent aphthous ulcers are thought to develop in FA patients due to neutropenia and anemia, as soft tissue ulcers heal within the weeks after blood transfusion [19]. Perdoncini NN et al. in Brazil compared the answers to the questionnaire regarding the periodontal health and clinical measurements of the periodontal status among individuals with FA and concluded that they were able to perceive gingivitis manifested by gingival bleeding [20].

Melanin pigmentation of the oral mucosa, traumatic lesions, gingival bleeding, dental biofilm, and gingival alterations were the main oral manifestations found in the study conducted by de Araujo MR et al. in Brazil [21].

Tekcicek M et al. investigated 26 FA children from the central region of Anatolia and find poor oral hygiene and $30 \%$-prevalence of dental caries, while radiological examination revealed microdontia, congenitally missing teeth, transposition, and supernumerary teeth in $44 \%, 26 \%, 9 \%$ and $4 \%$ of children, respectively [22]. Açikgöz A et al. investigated the oral health, including oral lesions, gingival and periodontal status in 15 children with FA from Ankara. They stated that the increased tendency toward periodontal disease might be due to anemia, leukopenia, and defective detoxification of oxygen radicals that are characteristic of FA itself, as well as to medications used during intense immunosuppressive treatment, such as steroids [23].

\section{Diagnostics}

FA may be suspected in a child with some of the signs listed above, combined with changes in clinical blood parameters. Other signs worth mentioning are hyperreflexia, hypogonadism, microcephaly, microphthalmia, strabismus, ptosis, nystagmus, and ear abnormalities. Macrocytosis, high mean cell volume, increased fetal hemoglobin, excess erythropoietin can be seen in the blood count of FA patients. There may be a deficiency of all blood cells, as well as a decrease in the number of platelets or leukocytes. The Diepoxybutane Test is used to make a diagnosis. The diagnosis can be made by means of a karyogram and karyotype to detect chromosomal abnormalities. The cellular composition of the bone marrow (myelogram) is examined for diagnosis clarification. The bone marrow biopsy reveals whether it is hypocellular or fatty [1]. In families where there have been cases of childbirth with FA, for all subsequent pregnancies, it is recommended a prenatal diagnosis to be done using cordocentesis (taking umbilical cord material) to find out the risk that the fetus has FA [24]. Furthermore, examination for FA is recommended when a child is born with skeletal abnormalities, especially arm abnormalities.

\section{Treatment}

Supportive therapy which involves transfusion of filtered erythrocytes and platelets (irradiated depleted leukocytes) is mainly used for treating FA. Chelation therapy due to iron overload, androgen hormones, as well as allogeneic heart transplantation are applied as well.

In November 2018, the first unrelated donor-hematopoietic stem cell transplantation in the Republic of North Macedonia was performed at the University Clinic of Hematology. It is one of the most modern and complex biological interventions that allows the most severe hematological diseases to be treated without surgery [25]. This opened the possibility to treat patients with FA in our country. Macedonian public health has entered the map of world and European medical centers for treating the most serious blood diseases. The Macedonian Bone Marrow Donor Registry, established within the Institute of Immunobiology and Human Genetics, Medical Faculty, Skopje, Macedonia, is a member of the World Marrow Donor Association.

Allogeneic bone marrow transplantation is the only chance to achieve normalization of blood formation in patients with FA [26]. In this case, it is highly desirable to perform the transplant while a patient is still young, optimally up to 10 years of age. If a patient has healthy siblings who are compatible as potential donors, then, transplantation is recommended. Patients with FA are particularly sensitive to chemotherapy (as well as radiotherapy); therefore, special conditioning protocols should be used [27]. FA patients with advanced oral cancer require a combination of surgery, radiotherapy, and chemotherapy for appropriate treatment. To reduce the adverse effects of radiation in FA patients with oral cancer or head and neck cancer, experimental tests are performed on FA mice irradiated with proton therapy to reduce the occurrence of inflammation of the oral mucosa [28]. Infection control is the most important part of dental treatment for FA patients. Radiographic examination is not recommended as X-rays may induce tumor development. If a patient is not prepared in advance, even a routine tooth extraction can cause a crisis. Non-invasive dental interventions do not require transfusion of platelets. Desmopressin and antifibrinolytic drugs are used in more invasive and shorter dental procedures, while platelet transfusions are used in more severe, long-lasting dental interventions.

\section{Treatment Prognosis}

The life expectancy of patients with FA depends on how severely the bone marrow function is impaired. Some patients live 30-40 years without treatment; however, many people die in childhood, either from the disease itself or from cancer 
that has resulted from the disease. Therefore, it is so important to have an allogeneic bone marrow transplant over time this is the only chance to restore normal blood formation and increase life expectancy.

Pediatric transplants from healthy compatible donor relatives (siblings) lead to success in most FA patients, although such transplants should be screened regularly for early detection of possible malignancies in various organs - the likelihood of their occurrence remains high, even after transplantation [29].

\section{Conclusions}

The interdisciplinary team of medical and dental specialists must be included in the medical and dental treatment of patients with FA. Medical doctors, especially hematologists, nephrologists, dermatovenerologists, ophthalmologists, otorhinolaryngologists, and dentists play an important role in treating FA. They have to work together in order to improve oral health-related quality of life of patients with FA. FA patients really need special dental care.

\section{Ethical Statement}

This article does not include any human participants and/or animals.

\section{Conflict of Interest}

The author declares that no conflicts exist.

\section{Financial Disclosure}

The author declared no financial support.

\section{References}

[1] Deaconu A, Vodă D, Bulucea D. Fanconi anemia case report of rare aplastic anemia at child. Acta Medica Marisiensis. 2014;60(3):125-128. Available from: https://doi.org/10.2478/amma-2014-0027

[2] Nepal M, Che R, Zhang J, Ma C, Fei P. Fanconi anemia signaling and cancer. Trends in Cancer. 2017;3(12):840-856. Available from: https://doi.org/10.1016/j.trecan.2017.10.005

[3] Zareifar S, Dastsooz H, Shahriari M, Faghihi MA, Shekarkhar G, Bordbar M, et al. A novel frameshift deletion in FANCF gene causing autosomal recessive Fanconi anemia: a case report. BMC Medical Genetics. 2019;20(1). Available from: https://doi.org/10.1186/s12881-019-0855-2

[4] Yang X, Zhang X, Jiao J, Zhang F, Pan Y, Wang Q, et al. Rare variants in FANCA induce premature ovarian insufficiency. Human Genetics. 2019;138(11-12):1227-1236. Available from: https://doi.org/10.1007/s00439-01902059-9
[5] Van den Hondel D, Wijers CHW, van Bever Y, de Klein A, Marcelis CLM, de Blaauw I, et al. Patients with anorectal malformation and upper limb anomalies: genetic evaluation is warranted. European Journal of Pediatrics. 2015;175(4):489-497. Available from: https://doi.org/10.1007/s00431-015-2655-9

[6] Savage SA, Walsh MF. Myelodysplastic syndrome, acute myeloid leukemia, and cancer surveillance in Fanconi anemia. Hematology/Oncology Clinics of North America. 2018;32(4):657-668. Available from: https://doi.org/10.1016/j.hoc.2018.04.002

[7] Furquim CP, Pivovar A, Amenábar JM, Bonfim C, Torres-Pereira CC. Oral cancer in Fanconi anemia: review of 121 cases. Critical Reviews in Oncology/Hematology. 2018;125:35-40. Available from: https://doi.org/10.1016/j.critrevonc.2018.02.013

[8] Touil D, Bouhouch R, Chebil RB, Oualha L, Douki N. Gingival bleeding in a child with Fanconi anemia: a case report and literature review. Case Reports in Dentistry. 2020;2020:3161053. Available from: https://doi.org/10.1155/2020/3161053

[9] Gaitán-Fonseca C, Frías-Muñoz M, Guerrero-de la Torre LE, et al. Pediatric dental care in Fanconi anemia: a case report. Odovtos-Int J Dent Sc. 2018;20(3):2531. Available from: https://www.medigraphic.com/cgibin/new/resumenI.cgi?IDARTICULO=82172

[10] Ballardin BS, Mobile RZ, Coracin FL, Ribeiro LL, Bonfim CMS, Schussel JL, et al. A case series of medication-related fibrovascular hyperplasia following hematopoietic stem cell transplantation for Fanconi anemia. Pediatric Transplantation. 2020. Available from: https://doi.org/10.1111/petr.13947

[11] Toptan T, Brusadelli MG, Turpin B, Witte DP, Surrallés J, Velleuer E, et al. Limited detection of human polyomaviruses in Fanconi anemia related squamous cell carcinoma. PLOS ONE. 2018;13(12):e0209235. Available from: https://doi.org/10.1371/journal.pone.0209235

[12] Pivovar A, Furquim CP, Bonfim C, Torres-Pereira CC. Mouth examination performance by children's parents and by adolescents in Fanconi anemia. Pediatric Blood \& Cancer. 2017;64(11):e26622. Available from: https://doi.org/10.1002/pbc.26622

[13] Available from: http://gslpublishers.org/journals/currentissues/119-Article.pdf

[14] Furquim CP, Soares GMS, Ribeiro LL, Azcarate-Peril MA, Butz N, Roach J, et al. The salivary microbiome and oral cancer risk: a pilot study in Fanconi anemia. Journal of Dental Research. 2016;96(3):292-299. Available from: https://doi.org/10.1177/0022034516678169 
[15] Velleuer E, Dietrich R, Pomjanski N, Santana Almeida Araujo IK, Silva de Araujo BE, Sroka I, et al. Diagnostic accuracy of brush biopsy-based cytology for the early detection of oral cancer and precursors in Fanconi anemia. Cancer Cytopathology. 2020;128(6):403-413. Available from: https://doi.org/10.1002/cncy.22249

[16] Lyko K, Lemes AL, Bonfim C, Torres-Pereira CC, Amenábar JM. Oral health status in children and adolescents with Fanconi anemia. Special Care in Dentistry. 2015;36(2):71-74. Available from: https://doi.org/10.1111/scd.12151

[17] Kaul R, Jain P, Saha S, Sarkar S. Fanconi anemia in pediatric dentistry: case report and review of literature. SRM J Res Dent Sci. 2017;8(2):92-96. Available from: https://www.srmjrds.in/text.asp?2017/8/2/92/207658

[18] Miranda F, Garib D, Netto BA, Lucena FS de, da Silva Santos PS. Orthodontic intervention in Fanconi's anemia: a case report. Special Care in Dentistry. 2020;40(4):382-389. Available from: https://doi.org/10.1111/scd.12487

[19] Goswami M, Bhushan U, Goswami M. Dental perspective of rare disease of Fanconi anemia: case report with review. Clinical Medicine Insights: Case Reports. 2016;9:CCRep.S37931. Available from: https://doi.org/10.4137/CCRep.S37931

[20] Perdoncini NN, Furquim CP, Bonfim CMS, Soares GMS, Torres-Pereira CC. Self-perception of periodontal health status among individuals with Fanconi anemia. Hematology, Transfusion and Cell Therapy. 2020. Available from: https://doi.org/10.1016/j.htct.2020.07.009

[21] De Araujo M, de Oliveira Ribas M, Koubik A, Mattioli T, de Lima A, França B. Fanconi's anemia: clinical and radiographic oral manifestations. Oral Diseases. 2007;13(3):291-295. Available from: https://doi.org/10.1111/j.1601-0825.2006.01282.x

[22] Tekcicek M, Tavil B, Cakar A et al. Oral and dental findings in children with Fanconi anemia. Pediatr Dent. 2007;29(3):248-252. Available from: https://www.ingentaconnect.com/openurl?genre=article \& issn $=0164-1263 \&$ volume $=29 \&$ issue $=3 \&$ spage $=248 \&$ aulast $=$ Tekcicek

[23] Açikgöz A, Özden FO, Fisgin T, Açikgöz G, Duru F, Yarali $\mathrm{N}$, et al. Oral and dental findings in Fanconi's anemia. Pediatric Hematology and Oncology. 2005;22(6):531-539. Available from: https://doi.org/10.1080/08880010591002413

[24] Lee HJ, Park S, Kang HJ, Jun JK, Lee JA, Lee DS, et al. A case report of Fanconi anemia diagnosed by genetic testing followed by prenatal diagnosis. Annals of Laboratory Medicine. 2012;32(5):380-384. Available from: https://doi.org/10.3343/alm.2012.32.5.380

[25] Panovska-Stavridis I, Pivkova-Veljanovska A, Ridova N, Stojanovski Z, Cadievski L, Trajkova S, et al. Molecular monitoring in acute myeloid leukemia patients undergoing matched unrelated donor - hematopoietic stem cell transplantation: single center experience. PRILOZI. 2020;41(3):5-12. Available from: https://doi.org/10.2478/prilozi-2020-0040

[26] Ebens CL, MacMillan ML, Wagner JE. Hematopoietic cell transplantation in Fanconi anemia: current evidence, challenges and recommendations. Expert Review of Hematology. 2016;10(1):81-97. Available from: https://doi.org/10.1080/17474086.2016.1268048

[27] Mehta PA, Davies SM, Leemhuis T, Myers K, Kernan NA, Prockop SE, et al. Radiation-free, alternative-donor HCT for Fanconi anemia patients: results from a prospective multi-institutional study. Blood. 2017;129(16):2308-2315. Available from: https://doi.org/10.1182/blood-2016-09-743112

[28] Quinn TJ, Ding X, Li X, Wilson GD, Buelow K, Sivananthan A, et al. Amelioration of mucositis in proton therapy of Fanconi anemia Fanca-/- mice by JP4039. In Vivo. 2019;33(6):1757-1766. Available from: https://doi.org/10.21873/invivo.11666

[29] Abram TJ, Pickering CR, Lang AK, Bass NE, Raja R, Meena C, et al. Risk stratification of oral potentially malignant disorders in fanconi anemia patients using autofluorescence imaging and cytology-on-a chip assay. Translational Oncology. 2018;11(2):477-486. Available from: https://doi.org/10.1016/j.tranon.2018.01.014

Received: 2021-03-26

Revised: 2021-04-28

Accepted: 2021-05-12 